\title{
Geografía y Minecraft: Potencialidades de una herramienta para la enseñanza a partir de un videojuego de mundo abierto
}

\section{Geography and Minecraft: a tool's potential for the teaching from a sandbox videograme}

\author{
Cristhian González, Graciano Barreda, Macarena Ortega, Cristian Ampuero, \\ Mónica Norambuena \\ cristhiang_93@hotmail.com,gracianogb@hotmail.com,maca.ortega.27@gmail.com, \\ campuero@uarg.unpa.edu.ar,mnorambuena@uarg.unpa.edu.ar \\ Universidad Nacional de la Patagonia Austral (UNPA), Unidad Académica Río Gallegos \\ (UARG), Escuela de Geografía, Ordenamiento Territorial y Geoprocesamiento. \\ Campus Universitario UARG - Av. Gregores y Piloto "Lero" Rivera S/N \\ Río Gallegos, Santa Cruz
}

Recibido: 28/05/2020. Aceptado: 25/06/2021

\section{RESUMEN}

Minecraft es uno de los videojuegos más difundidos en la actualidad, a 10 años de su lanzamiento, luego de su segundo auge. Clasificado como un juego de tipo "mundo abierto", no posee un objetivo en específico y le permite al usuario la libertad de jugar a su manera. La mecánica del juego se centra en la colocación y destrucción de bloques de diferentes elementos de la naturaleza como rocas, minerales, maderas, etc. Por este motivo, permitir la identificación de elementos geográficos, se constituyen como una potencial herramienta para la enseñanza de esta ciencia, desde la perspectiva del "game based learning" (aprender jugando). El objetivo del trabajo es identificar rasgos geográficos existentes en el videojuego, con el fin de destacar la potencialidad de este material lúdico como recurso didáctico para la enseñanza de la Geografía. Metodológicamente, se recurrió a la búsqueda, lectura comprensiva y selección bibliográfica sobre el origen y antecedentes del videojuego y su uso como herramienta didáctica en las Ciencias Sociales y Exactas. Posteriormente, a partir de la experiencia como jugadores, se identificaron los aspectos geográficos presentes en el juego, para luego clasificarlos de acuerdo a los principales contenidos y temáticas de la Geografía. Como resultado del trabajo, se destacan las potencialidades de Minecraft como herramienta pedagógico-didáctica significativa, sobre todo para la escuela secundaria, al ser los estudiantes de este nivel el grupo etario que el juego tiene como destinatario principal y que permite profundizar en conceptos del Espacio Geográfico, sus componentes y sus características.

Palabras clave: Espacio Geográfico; Espacio Virtual; Entretenimiento; Aprender Jugando; Enseñanza de la Geografía.

\begin{abstract}
After 10 years of its launching, Minecraft is one of the most relevant video games, after its second wave of popularity. Under the category of "sandbox" due to its lack of endgame, giving the player the freedom to play anyway they want. The game's mechanic focuses on the placement and destruction of blocks of different kinds, like rock, minerals, wood and others.
\end{abstract}


For this reason, allowing the identification of geographical elements, serves as a tool of teaching for this science, from the "game based learning" perspective. The goal of this work is to recognize geographical features present in the game with the purpose of highlighting it as a possible didactic tool for the teaching and divulgation of the geography in the educational field. From the methodological standpoint, it resorted to searching bibliography about the game conception, video-game backgrounds and it uses as didactic tools in the sciences. Later, with experience as players, they were identified geographical aspects in the game to classify them in Geography's sub-branches. As a result of the work, it stands out that Minecraft has a great educational value, especially in high schools, due to being the age group targeted by the game, and it allows to deepen the notion of geographical space, its components and its characteristics.

Keywords: Geographical Space; Virtual Space; Entertainment; Learn Playing; Geography Teaching.

\section{INTRODUCCIÓN}

El videojuego Minecraft es de tipo "Sandbox", en el cual el jugador tiene la libertad de experimentar y vivenciar sin restricciones. Su dinámica consiste en la colocación y destrucción de bloques de diferentes elementos de la naturaleza, para recolectar recursos y crear nuevos tipos de bloques en un mundo generado procedimentalmente.

El tema central de este artículo, surge a partir del auge del videojuego en el año 2019, generado, en gran parte, por creadores de contenido audiovisual en diferentes plataformas de videos y streaming.

Se describe el potencial que tiene para ser utilizado como una herramienta pedagógicodidáctica en un ámbito institucional áulico, por sus rasgos geográficos, con el fin de que sea adoptada por docentes para su posible aplicación.

El videojuego Minecraft tiene la característica de ser un game-based learning (GBL), esto refiere que no sólo integra los elementos del juego, sino que incluye la formación en sí misma con actividades a desarrollar, se puede aprender a través del mismo en un entorno en el cual se pueden adquirir, mejorar y practicar habilidades, ayudar a la retención y compromiso con los temas de la Geografía y volverse un proceso de aprendizaje divertido y desafiante.

Los elementos de carácter geográfico que se identifican en Minecraft, pueden ser relacionados con los contenidos considerados dentro de los Núcleos de Aprendizajes Prioritarios (NAP) establecidos por el Consejo Federal de Cultura y Educación (CFCyE) de la Nación, emitidos en la Resolución $\mathrm{N}^{\circ} 214 / 04$, en la que se acuerda la identificación de los NAP y el compromiso de realizar las acciones que sean necesarias para favorecer y posibilitar el acceso a esos aprendizajes. En términos generales, los NAP son el conjunto de saberes centrales, relevantes y significativos que, incorporados como objetos de enseñanza, contribuyen a desarrollar, construir y ampliar las posibilidades cognitivas, expresivas y sociales que los alumnos ponen en juego y recrean cotidianamente en su encuentro con la cultura, enriqueciendo de ese modo la experiencia personal y social en sentido amplio (Ministerio de Educación, Ciencia y Tecnología, 2004:7). 
Los NAP en el Campo de Formación General del Ciclo Orientado de Educación Secundaria define a la Geografía dentro del área de las Ciencias Sociales, allí se recomienda que las propuestas de enseñanza consideren la articulación de múltiples escalas geográficas, el uso de cartografía pertinente a cada tema, la selección y uso crítico de diversas fuentes de información cuantitativas y cualitativas, el trabajo con estudios de caso, situaciones-problema, simulaciones, proyectos de investigación y participación comunitaria. En este caso se integrarían más los aspectos de la dimensión socio-demográfica de los territorios y la dimensión ambiental de los territorios.

Se espera, que considerar a este videojuego como una potencial herramienta pedagógicodidáctica, contribuya a garantizar esas intenciones educativas al ser un instrumento útil para entender y actuar con inventiva, promoviendo el sentido crítico y la creatividad, aspirando a que enriquezca las experiencias educativas.

El objetivo del trabajo es identificar los diferentes rasgos geográficos existentes en el videojuego, con el fin de destacar la potencialidad de este material lúdico como recurso didáctico para la enseñanza de la Geografía y, particularmente, la comprensión del Espacio Geográfico, a partir de sus componentes y características.

Desde lo metodológico, se recurrió a la búsqueda, lectura comprensiva y selección de bibliografía respecto al origen y antecedentes del videojuego, su uso como recurso didáctico, conceptos geográficos relevantes y su relación con los NAP. Posteriormente, a partir de la experiencia como jugadores, se identificaron los aspectos geográficos presentes en el juego, para luego clasificarlos de acuerdo a contenidos y temáticas abordadas desde la Geografía.

\section{MARCOS DE REFERENCIA}

\section{Surgimiento, evolución, componentes y características del juego}

Minecraft es un videojuego que se centra en la colocación y destrucción de bloques, que conforman el mundo dentro del juego. Fue creado el 17 de mayo de 2009 por el sueco Markus Persson, conocido como "Notch", en un principio y luego por su empresa indie Mojang AB.

Persson manifestó el 30 de octubre de 2009 en su blog personal en "Tumblr" que se inspiró en el videojuego multijugador basado en bloques "Infiniminer", desarrollado y distribuido por Zachtronics Industries y diseñado por Zachary Barth, en el cual el jugador es un minero que debe conseguir minerales al cavar en la superficie del mapa. Persson, M. (2011), por medio de su cuenta verificada en la red social “Twitter” (@Notch), declaró que "Dungeon Keeper [...] es una de las inspiraciones de Minecraft" (Persson, M. 2011). Dentro de la comunidad gamer de Minecraft, destacan que otras influencias de Notch fueron: "Dwarf Fortress" y un proyecto previo de Notch llamado "RubyDung”. (Página Minecraft Wiki)

Todos los avances creativos del juego, eran presentados por Notch en videos en su canal de Youtube, en el que consiguió popularidad en la plataforma, al punto de lograr, luego de un mes, dejar su trabajo y dedicarse plenamente al desarrollo del juego (Marca eSport, 2019). En diciembre de 2010, se puso a disposición en el mercado, una versión beta del juego y el 18 de noviembre de 2011, con un aumento en el precio, llegó una versión alpha, con mejoras considerables en la calidad del juego y disponible para distintas consolas y plataformas. Este 
evento, dio comienzo al primer auge de popularidad del juego, que obtuvo más de un millón de jugadores ese año y superó las diez millones y medio de copias en la versión de descarga hasta mayo de 2013, según las estadísticas de Mojang, citadas en Gértrudix y Gértrudix (2013:130).

La mecánica del videojuego comienza con la posibilidad de seleccionar "jugar en solitario o multijugador", en distintos modos de juego:

1) Supervivencia: los jugadores deben conseguir todos los materiales que quieran utilizar en la construcción. Incluye la barra de salud y daño y, el inventario.

2) Creativo: la mayoría de los bloques que se pueden utilizar para la construcción se tienen desde el comienzo y en cantidades infinitas. El personaje no puede morir en el juego. El único objetivo es la construcción.

3) Aventura: no se puede romper ni colocar ningún tipo de bloque, solo se permite usar palancas, placas de presión, botones, puertas de madera, abrir cofres, hornos y dispensadores, utilizar armas y herramientas, pero solo para atacar mobs. Este modo se suele usar en mapas de aventura creados por terceros.

4) Extremo: se juega de la misma forma que en el modo de supervivencia. El nivel de dificultad está permanentemente en "extremo" y el mundo es eliminado después de la muerte del jugador.

5) Espectador: se puede volar, atravesar bloques y entidades, pero no interactuar con los bloques, activar mecanismos de redstone ni usar objetos, entre otras acciones.

Una de las características principales que posee el juego, es la capacidad de modificarlo, ya sea mediante "mods", que alteran o agregan mecánicas al mismo, o a través de texturas que consisten únicamente en cambios estéticos, sin alterar la jugabilidad.

Minecraft se encuentra disponible en tres versiones:

- "Minecraft: Java Edition", es la original del juego y está desarrollada por Mojang AB para los sistemas operativos: Windows, macOS y Linux. Como su nombre lo sugiere, está escrita en lenguaje Java, su código es más sencillo de modificar que otras versiones. Cuenta con la mayor cantidad de mods y servidores personales.

- "Bedrock Edition", hace referencia a una familia multiplataforma de ediciones del juego desarrolladas por Mojang AB, Xbox Game Studios, 4J Studios y SkyBox Labs, anterior a este término se la refería como "Pocket Edition", "MCPE" o "Pocket/Windows 10 Edition". Aunque todas las versiones Bedrock son prácticamente idénticas, su precio varía dependiendo de la plataforma. Ésta difiere de Java en varias formas, en los gráficos, la generación de terreno, ítems exclusivos, comportamiento de mobs (de mobile al tratarse de "entidades móviles del juego") y la cantidad de jugadores en línea permitidos.

- "Minecraft: Education Edition", surge del mod "MinecraftEdu" creado por TeacherGaming en el 2011 y adquirido por Microsoft en 2016. Desarrollado por Mojang AB y Xbox Game Studios, es la versión del juego diseñada específicamente para ser utilizada en el aula y basada en Bedrock Edition. Fue lanzada a docentes e instituciones capaces de comprobar que pertenecen a un entorno educativo o académico y agrega funciones al juego que lo hacen más accesible y efectivo. Entre las funciones se encuentra la facilidad de colaboración entre compañeros de clase, la habilidad de agregar personajes no jugables, o NPC por sus siglas en inglés (Non-playable character) que funcionan como guías para los estudiantes en el juego, la posibilidad de realizar capturas de pantallas para compartirlas en un portafolio, "pizarrones" virtuales para comunicar instrucciones en el juego, tutoriales, un modo "clase" que le permite al 
docente ver la ubicación de los alumnos en el mundo y poder comunicarse con ellos, entre otras.

El juego recibe actualizaciones periódicamente, que agregan o expanden mecánicas. Algunas importantes son:

- 1.0.0: La primera, agrega el bioma de setas, aldeanos, "The End" y magma.

- 1.2.1: Agrega el bioma de jungla y minas abandonadas.

- 1.3.1: Añade aldeas del desierto, esmeraldas y diferentes tipos de templos.

- 1.6: "The Horse Update" la primera actualización en ser nombrada. Agrega caballos, burros mulas.

- 1.7.2: "The Update that Changed the World" agrega varios biomas, océano profundo, colinas extremas, taiga, savanna, mesa, birch forest, más flores

- 1.8: "Bountiful Update", agrega herramientas de cartografía, diorita, andesita y granito

- 1.13: "Te Update Aquatic" se enfoca en los océanos, agregan flora y fauna marina y estructuras sumergidas como ruinas y naufragios.

- 1.14: "Village and Pillage" actualiza y expande las aldeas, actualiza la taiga y agrega el bosque de bambú.

Durante este primer auge, aparecieron múltiples "Let's Plays" o "Gameplays", videos donde personas se graban mientras juegan y reaccionan para posteriormente subirlo en plataformas como YouTube, o transmitir en vivo en servicios tales como Twitch. Varios creadores de contenido audiovisual de habla hispana tuvieron sus inicios en las plataformas cuyo contenido se centraba en el juego y de los cuales varios se encuentran entre los youtubers con más suscriptores en la plataforma. Con el paso del tiempo, la popularidad del juego se vio en declive (Fig. 1) y los creadores pasaron a crear contenido basado en videojuegos populares, como por ejemplo "Fortnite", videojuego desarrollado por Epic Games y People Can Fly, lanzado en julio de 2017 (Fig. 2).

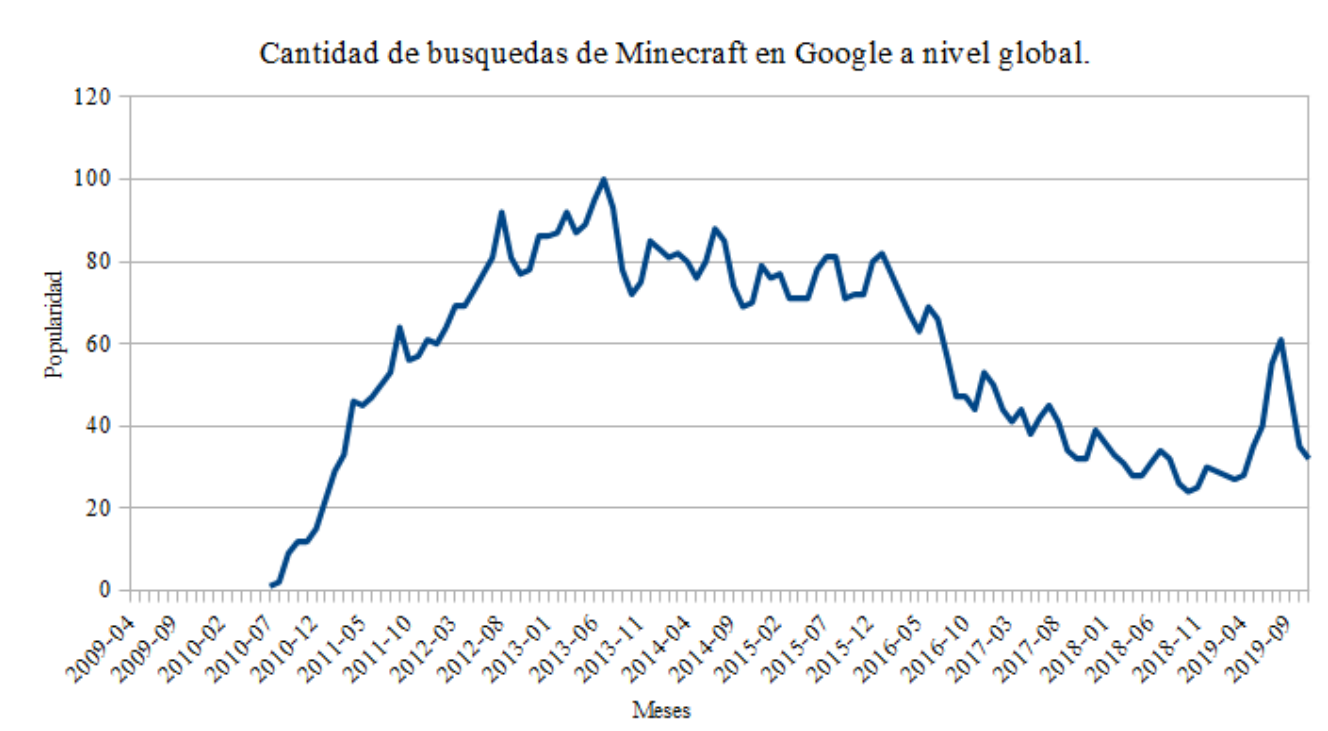

Fig. 1: Cantidad de búsquedas de Minecraft en Google a nivel global

Elaborado por Barreda, G. y González, C. a partir de información obtenida por Google Trends 


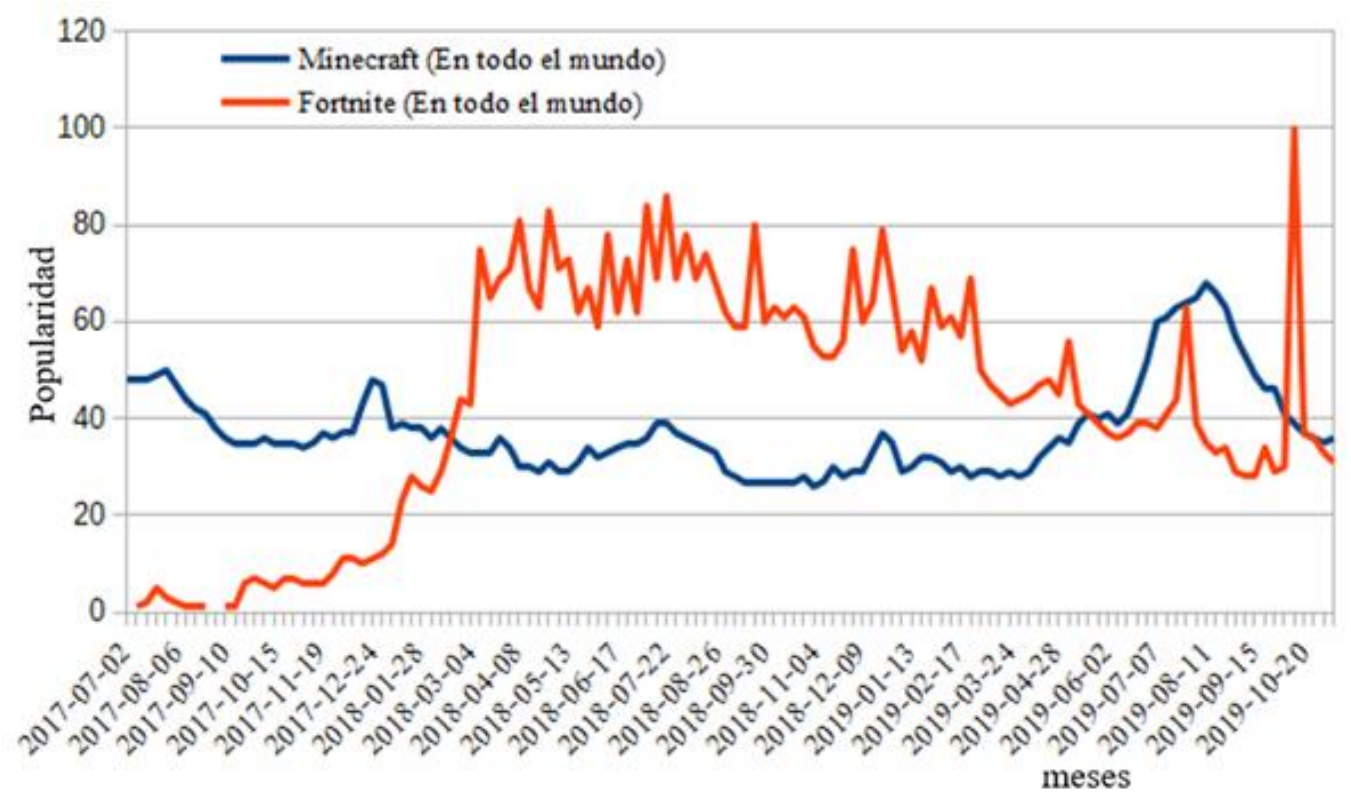

Fig. 2: Cantidad de búsquedas de Minecraft y Fortnite en Google a nivel global Elaborado por Barreda, G. a partir de información obtenida por Google Trends

En septiembre de 2014, la empresa Mojang AB fue comprada por Microsoft por un valor de 2500 millones USD, lo que provocó el alejamiento de Persson de la compañía y dejó a Jens "Jeb" Bergensten y Nathan "Dinnerbone" Adams como diseñadores del juego.

A mediados de junio de 2019, Minecraft presentó un nuevo auge y en parte se debe a que creadores de contenido audiovisual en diferentes plataformas, comenzaron a jugar nuevamente el videojuego. Tal es el caso del youtuber sueco Felix Arvid Ulf Kjellberg más conocido como "Pewdiepie", quien el 21 de junio de ese año, comenzó una serie en su canal de YouTube. Su video titulado "Minecraft Part 1" sobrepasó los 34 millones de vistas. Actualmente, su serie de Minecraft cuenta con más de 70 videos.

Pewdiepie, durante este período, colaboró con otros creadores de contenido como el irlandés Seán William McLoughlin conocido en YouTube como "Jacksepticeye", participó en el evento "Minecraft Monday" donde realizó equipo con James Charles Dickinson, el youtuber maquillador e influencer. En julio de este año jugó Minecraft junto al actor, músico, comediante y productor Thomas Jacob Black, conocido como Jack Black.

Dentro de la comunidad hispanohablante, se llevan a cabo series entre personalidades destacadas de Internet. Una de las más conocidas es "Karmaland", con la colaboración de reconocidos youtubers y streamers. Esta comenzó en octubre de 2019, en diversas plataformas (Youtube, Twitch y Facebook) y cuenta con más de 90 episodios.

Con respecto a la disponibilidad y compatibilidad, el videojuego se encuentra disponible para: Windows, Apple iOS, Linux, Android, IOS, Xbox (360 y one), PlayStation (3, 4 y vita), Wii U y Nintendo Switch. (Página oficial de Minecraft, 2019)

En mayo del 2019 se anunció Minecraft Earth, un juego de realidad aumentada (similar a Pokémon Go), el cual utiliza la información de OpenStreetMap y se encuentra disponible para dispositivos móviles (IOS y Android), sistema operativo Windows y PlayStation 4. 


\section{Marco Teórico - Conceptual}

Bosque Maurel y García Bellesteros (2003), consideran la obra de Milton Santos y sus definiciones respecto a la Geografía. El geógrafo brasileño menciona que "pese a que la Geografía sea una de las disciplinas sociales en la que se han producido más debates sobre su contenido [...] en la sociedad "perdura la vieja noción de la Geografía corográfica como enumeración de sitios y lugares y como descripción no siempre lúcida de accidentes denominados geográficos: ríos, océanos, lagos, montañas...”. Por esa razón y la tensión consiguiente, "los geógrafos se quejan de que esta criatura no permite el reconocimiento de su verdadero trabajo y les da una imagen desfavorable"... E insiste y se ratifica en su preocupación por definir con justeza su visión de los objetivos del geógrafo y de su ciencia, "la Geografía se ocupa de las relaciones entre la sociedad y su entorno, desde la comunidad humana y el planeta hasta la escala del menor lugar" por lo cual "las subdivisiones de la Geografía... a veces conducen a dejar en segundo plano su carácter globalizador y totalizador”. Además, en el cambio hacia el siglo XXI y el Tercer Milenio, "las realidades geográficas también se renuevan, contribuyendo paralelamente a la emergencia de nuevos conceptos". (Bosque Maurel y García Ballesteros, 2003:13)

Por su parte, Rodríguez de González, Parra de Juri y Corazza, citan una definición sencilla de la Geografía propuesta por Ortega Valcárcel, quien dice "...la Geografía es una disciplina situada en el centro de las preocupaciones de la sociedad de hoy... se debate entre los condicionantes de su pasado y las posibilidades del futuro". (Rodríguez de González et al, 2008:11)

La Geografía, históricamente se ha relacionado con otras ciencias y disciplinas, tanto naturales como sociales y exactas, desde la Historia hasta las Matemáticas considera aspectos, conceptos y temas que están relacionados con esta ciencia. Los temas de estudio de la Geografía son muchos y muy variados; entre estos, pone el foco de atención en los modos de organización del espacio terrestre, la distribución de los elementos que componen el paisaje, sus formas, sus poblaciones, sólo por mencionar algunos. Las relaciones que se producen entre la naturaleza y la sociedad a través del tiempo histórico, son las que transforman la superficie terrestre, originando el Espacio Geográfico, que junto con el paisaje, son conceptos clave, objeto de estudio de la Geografía como ciencia social.

En su desarrollo y evolución hasta la actualidad, la Geografía consideró diferentes formas y corrientes para el abordaje de los hechos que se manifestaban en el Espacio Geográfico. En su enseñanza, tradicionalmente, se han considerado campos dentro de la Geografía asociadas a ciencias auxiliares se dividían en dos grandes áreas: la Geografía física y la Geografía humana. Sin embargo, si bien todavía es posible encontrar esta división, actualmente dentro del ámbito de las Ciencias Sociales y de la Geografía, se llevan adelante prácticas que integran los contenidos y temas motivo de estudio, apelando al análisis y la formación crítica de los geógrafos. Sumado a lo anterior, la cartografía atraviesa de manera transversal, cada hecho geográfico a analizar.

Como se indicó anteriormente, los NAP son "un conjunto de saberes centrales, relevantes y significativos que, incorporados como objetos de enseñanza, contribuyen a desarrollar, construir y ampliar las posibilidades cognitivas, expresivas y sociales que los niños ponen en juego y que recrean cotidianamente en su encuentro con la cultura, enriqueciendo de ese modo la experiencia personal y social en sentido amplio". Estos son un organizador de la enseñanza 
orientada a promover múltiples y ricos procesos de construcción de conocimientos, potenciando las posibilidades de la infancia, pero atendiendo a la vez ritmos y estilos de aprendizaje singulares a través de la creación de múltiples ambientes y condiciones para que ello ocurra. (Ministerio de Educación, Ciencia y Tecnología, 2004:7)

Asimismo, los NAP contemplan el uso crítico y responsable de las TIC y su valoración como herramientas clave para el acceso a nuevas formas de abordaje y presentación de la información (Ministerio de Educación, Ciencia y Tecnología, 2004:15).

En el apartado dedicado a la Geografía desde los NAP, se propone el uso de cartografía pertinente en cada temática. También se considera, dentro de la dimensión ambiental de los territorios, el conocimiento de los diversos modos de valoración que las sociedades hacen de los elementos y de las condiciones naturales de los grandes conjuntos ambientales, en los procesos de construcción del territorio (Ministerio de Educación, Ciencia y Tecnología, 2004:20).

Por otra parte, Mastrangelo (2009) realiza una amplia recopilación respecto al concepto de Recursos Naturales, en este sentido, la autora plantea que estos "...no son dados de manera objetiva, sino que se relacionan con necesidades sociales específicas de manera que, tanto históricamente como en el presente, han sido objeto de disputa entre actores en posiciones sociales desiguales. La propia noción de "recursos naturales" ha ido modificando su significado. Los manuales de economía (Martínez Alier, 1991; Naredo; Parra, 1993) y Geografía Económica (Carnevali, 1983; Roccatagliata, 2001) definen al recurso "natural" como los "bienes materiales que proporciona la naturaleza sin alteración por parte del hombre". Y los clasifican en bienes fondo (stock) y bienes flujo. Algunos recursos naturales se consideran bienes de fondo, porque se agotarán si se los apropia a una tasa mayor a la de su renovación. Mientras que otros tienen la lógica de los bienes flujo, y por tanto se renuevan. De acuerdo a la disponibilidad en el tiempo, la tasa de generación o regeneración y el ritmo de uso o consumo, se determina qué recurso es renovable y cual otro es no renovable." (Mastrangelo, 2009)

Con respecto a Minecraft, el mismo es un videojuego de "mundo abierto" o "Sandbox". Gértrudix y Gértrudix (2013) mencionan que los Sandbox son "entornos de juego construidos en los que los participantes disponen de una gran libertad de acción y exploración. Aunque el juego está determinado por unos principios generales que establecen sus límites y posibilidades, los usuarios tienen una notable capacidad de elección para definir sus objetivos y generar de forma activa la secuencia narrativa que desean crear en el proceso de juego, se establece un marco abierto, no lineal". Asimismo, "los jugadores gozan de una amplia libertad, lo que no impide que, de forma natural, especialmente en las opciones multijugador, estos se agreguen de forma espontánea en colectivos y sigan tendencias de juego similares. El entorno suele ser especialmente lábil y flexible, permite que los jugadores puedan crear, modificar o eliminar distintos elementos, incluso superar los límites establecidos en el juego y, con ello, configurar nuevas dimensiones que no estaban definidas originalmente o controladas por el creador original” (Gértrudix y Gértrudix, 2013:127).

Las definiciones del aprendizaje basado en juegos enfatizan, principalmente, que son un tipo con resultados de aprendizaje definidos (Shaffer et al, 2005). Usualmente se asume que el juego es un videojuego digital, pero no siempre es el caso. Una definición de juego es, "un sistema 
en el que los jugadores participan en un conflicto artificial, definido por reglas, que resulta en un resultado cuantificable" (Salen y Zimmerman, 2004:414).

El GBL, traducido como "aprendizaje basado en juegos", se basa en un aprendizaje constructivista que le entrega al estudiante las herramientas necesarias para construir sus propios métodos para resolver problemas. Esto implica un proceso interactivo entre el alumno y su entorno. La práctica sin riesgo, el aprendizaje experiencial y la interacción son los pilares de la teoría del game-based learning (Gamelearn Team, s/f).

Gamelearn Team también sostienen que uno de los puntos fuertes del GBL es el reconocimiento de que los juegos captan la atención de los estudiantes. El enfoque motivador de los juegos convierte el proceso de aprendizaje en algo dinámico e interesante cuyo atractivo se mantiene durante todo el desarrollo. La teoría del GBL no puede ignorar los beneficios creativos que proporcionan las nuevas formas de aprender, el juego potencia dicha creatividad y motivación mediante el planteamiento de retos y problemáticas que los alumnos deben resolver utilizando su imaginación.

Cabe destacar la diferencia entre GBL y Gamificación, que comúnmente se usan como sinónimos. Gamificación, o Ludificación, consiste en aplicar los principios del diseño de los videojuegos, mecánicas y elementos propios de los videojuegos (tales como recompensas, objetivos, interacciones, puntuaciones, etc.) en cualquier proceso, más allá del propio contexto de los videojuegos (Gallego et al. 2014). Generalmente, se toma contenido ya existente y se le añaden los elementos propios del juego, como por ejemplo medallas, puntos, barras de progreso. En contraste, el GBL no solo integra los elementos del juego, sino que la formación en sí misma se convierte en el juego o, dicho de otra manera, es aprender a través de juegos. Suele ser utilizado cuando se tratan contenidos más complejos, con un alto nivel de interactividad, se destacan el uso de la narrativa, competitividad o la posibilidad de experimentar.

McFarlane et al. (2002), citado en García Fernández (2005:12), comenta que "los videojuegos allanan la adquisición y el desarrollo de ciertas estrategias fundamentales para el aprendizaje: la resolución de problemas, el aprendizaje de secuencias, el razonamiento deductivo y la memorización. También, simplifican la realización de trabajos en grupo de tipo cooperativo o en colaboración y el aprendizaje basado en la resolución de tareas".

García Fernández (2005:11) sostiene que “...desde el punto de vista educativo los videojuegos, permiten una enseñanza eficaz, en bastantes ocasiones mucho mejor que el actual sistema escolar. No en vano, desde el punto de vista de la teoría del aprendizaje social, algunos de los factores que fomentan la motivación son intrínsecos a los videojuegos". El autor menciona algunos ejemplos como: dificultad decreciente y progresiva de las habilidades, adaptadas al ritmo de cada uno, con la posibilidad de repetir y corregir errores; estimulación simultánea a múltiples niveles: visual, auditivo, etc.; identificación con héroes o personajes que fomentan la imitación; entre otros.

Greenfield (2000), citado en García Fernández (2005:12), investigó acerca del aprendizaje producido en niños y niñas de 12 a 16 años que utilizaron videojuegos del tipo "aventuras", y llegó a la conclusión que la utilización de videojuegos para el aprendizaje aumenta las estrategias de lectura visual de imágenes y del espacio tridimensional. A su vez, ayudan con el 
aprendizaje por observación y desarrollan estrategias para recibir y procesar información recibida de varias fuentes en simultáneo (procesamiento en paralelo).

Se encontraron trabajos de investigación orientados al GBL. En algunos casos destinados a otras Ciencias Sociales (por ej. Historia), o Ciencias Exactas (por ej. Matemática) y los trabajos destinados a la Geografía eran con mundos previamente diseñados con fines educativos. Se considera que el mundo creado aleatoriamente por Minecraft es Geográfico, sin necesidad de modificaciones.

\section{RESULTADOS, ANÁLISIS Y DISCUSIÓN}

\section{Metodología}

En primer lugar, se llevó a cabo una búsqueda, lectura comprensiva y selección de bibliografía específica, en bibliotecas reales y virtuales, para profundizar sobre el origen y la historia de Minecraft, conceptos de GBL, aprendizaje basado en juegos, la aplicación y uso de Minecraft como herramienta pedagógica-didáctica en Ciencias Sociales, Exactas y en la propia Geografía. Posteriormente, en trabajo en gabinete, se ingresó al juego con la finalidad de relevar e identificar todos los aspectos geográficos que se encontraban presentes en el mismo. Para ello, se utilizaron las versiones 1.14.0 para el sistema operativo "Windows" y 1.12.0.6 para Android. Por último, una vez finalizada la búsqueda de los elementos geográficos, se los clasificó teniendo en cuenta los campos y temáticas de interés que se tienen en cuenta dentro de la Geografía, para su posterior análisis y correlación mediante sustento teórico en cada una.

\section{Resultados}

Al ingresar al juego relevaron e identificaron un total de siete (7) rasgos y/o elementos geográficos presentes en el mundo abierto de Minecraft. Estos son: Cartografía, cuatro que pueden relacionarse con la Naturaleza o dentro de la Geografía Física: Biogeografía, Geomorfología (con subcategoría en procesos endógenos y procesos exógenos), Climatología, Hidrografía y dos que se pueden considerar en relación a la Sociedad o dentro de la Geografía humana: Geografía Rural y Geografía Urbana.

Dentro del juego, ciertos bloques son más comunes de encontrar que otros, ubicándolos dentro de una escala de importancia o valor para el jugador. Algunos bloques son necesarios para la creación de otros que facilitan ciertas tareas. Asimismo, existen bloques solo presentes en determinados biomas, provocando que estos sean más deseables de encontrar en el mundo. Como es el jugador quien le da este valor a los mismos, puede ser utilizado como introducción o ejemplo del concepto de recurso natural y el valor que la sociedad le da según su utilidad.

\section{Cartografía}

El juego posee el sistema de coordenadas para la localización del espacio. Se tiene en cuenta "XYZ", donde "X" y "Z" corresponde a la latitud y longitud, mientras que "Y" indica la altitud con respecto del nivel del mar. En el caso de la Fig. 3, el punto de disparo de la flecha corresponde a X 4496; Y 84; Z 512, mientras que el punto de impacto de la flecha es X 4480; Y 78; Z 522. La variación de X es de 16, de Y: 6 y de Z: 10. El uso constante de coordenadas en el juego, mediante las cuales el jugador puede recordar la ubicación de elementos en el 
mundo facilita la comprensión del concepto de localización a través de coordenadas geográficas y ubicación del Espacio Geográfico real.
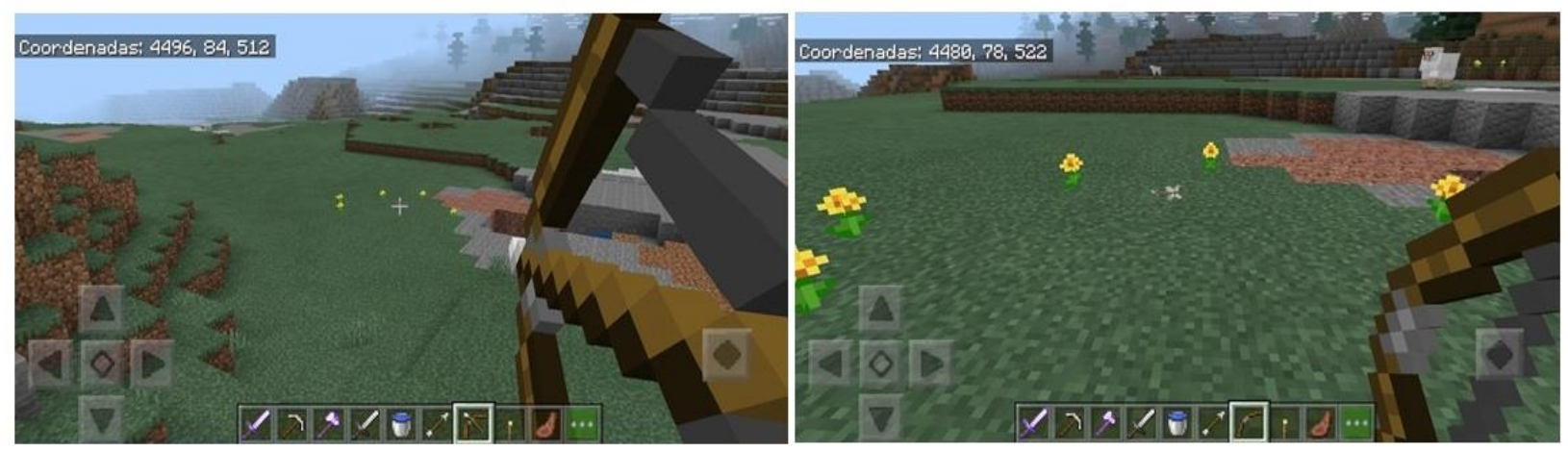

Fig. 3: Coordenadas XYZ.

Fuente: Captura de pantalla obtenida de Minecraft por los autores.

Por medio de la mesa de trabajo, se puede crear una "mesa de cartografía" (Fig. 4) con la finalidad de realizar mapas, en los cuales se muestran grandes extensiones del terreno, se tienen en cuenta las construcciones, las aldeas, la vegetación, etc. Los mapas pueden realizarse en distintas escalas, mientras menor sea la escala, mayor es el detalle que se aprecia y mientras mayor sea el área representada, menor es el detalle que tienen los mapas. Esta característica le ayuda al jugador a comprender conceptos básicos como la escala cartográfica, conocimiento necesario para lectura y creación de mapas y con el simple nombre relaciona la cartografía con la realización de mapas.

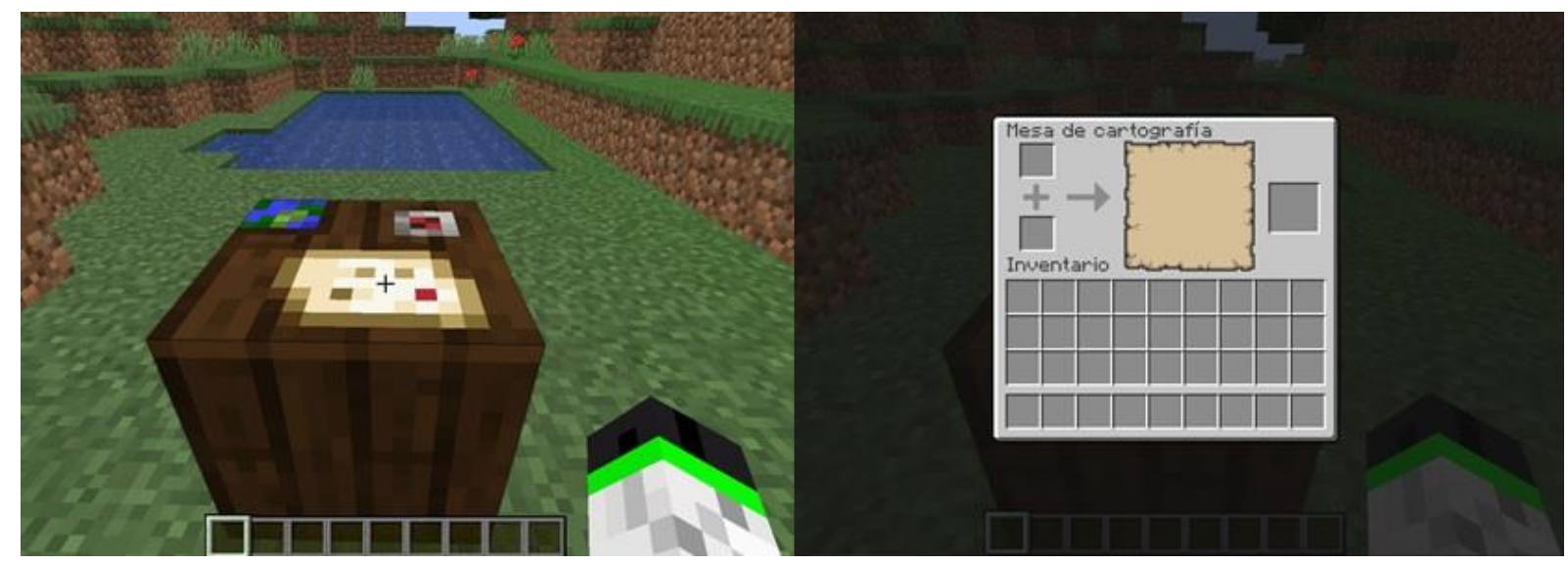

Fig. 4: Mesa de cartografía

Fuente: Captura de pantalla obtenida de Minecraft por los autores.

Según Amorós Hernández (2016) se pueden destacar cuatro fines principales de la cartografía como elemento didáctico: ayuda a localizar lugares, fija la situación y posición en relación con unas coordenadas geográficas; sirve para señalar un itinerario, permite trazar rutas de un lugar a otro; muestra la estructura de un área determinada y permite conocer cuál es el paisaje del área y cómo se distribuyen los elementos y; finalmente, es utilizado para almacenar la información o presentarla. Desde el punto de vista educativo, la cartografía trabajada representa una herramienta valiosa para el estudiante, a fin de aprender sobre el espacio, reflexionar y desarrollar la capacidad de manipular mapas, tener conceptos y lenguaje geográfico simbólico. 


\section{Biogeografía}

El juego define a los biomas como regiones en el mundo de Minecraft que se diferencian por: características geográficas, flora, fauna, temperatura, altitud, nivel de humedad, color del cielo y color del follaje, lo cual determina distintos ecosistemas dentro de un mundo (por ej. bosques, junglas, desiertos, llanuras, etc.). Los biomas se dividen en 5 categorías según su temperatura: de nieve, fríos, medios, secos/cálidos y neutros (Figs. 5 y 6). Estos se separan de esta forma, para evitar que los biomas con grandes diferencias de temperatura se ubiquen uno al lado del otro (como la taiga fría junto al desierto) y para permitir que los biomas con temperaturas similares, se sitúan uno al lado del otro con más frecuencia (como bosques y pantanos).

Esta definición dentro del juego es mucho más simplista en contraste con la realidad, debido a la naturaleza sistemática de la programación del juego. Olivier (1981) definió un bioma como un conjunto de ecosistemas con una composición de flora y fauna con un funcionamiento y un ajuste al clima y al suelo característicos. Lo que la definición del juego sí replica es la distinción que este autor hace al decir que, generalmente, los biomas se encuentran definidos por estructuras de vegetación, el clima, la latitud y altitud. Por ejemplo, en el juego, el bioma "jungla" es un bioma frondoso y cálido lleno de vegetación densa en el cual jugador puede encontrar exclusivamente loros, pandas ocelotes, cocoa, melones, bambúes, enredaderas y árboles de jungla, los cuales son los de mayor tamaño en el juego. La jungla, al igual que su contraparte real, es el bioma con mayor diversidad de especies animales y vegetales.

En Minecraft hay 38 biomas principales en el Mundo principal (dos sin uso), uno en "El inframundo", uno en "El End" (los cuales son biomas ficticios) y 22 biomas técnicos, lo que da un total de 62 biomas diferentes. Los biomas se pueden distinguir por el color de la vegetación (hierba y hojas), tipo de vegetación (helechos y bayas en la taiga, nenúfares, hongos y orquídeas en los pantanos), animales (lobos, zorros y liebres en la tundra; caballos, vacas, ovejas y burros en las planicies). Los biomas se generan aleatoriamente mediante el sistema de semillas.

Los nombres que el juego le da a los biomas suelen ser anticuados y estereotipados (como jungla en lugar de selva o bosque lluvioso) pero cumplen la función de familiarizar al jugador con diferentes tipos de biomas, los recursos naturales únicos que cada uno de ellos presentan, y las condiciones naturales que se encuentran en el espacio que permiten la generación de determinados biomas en la realidad.
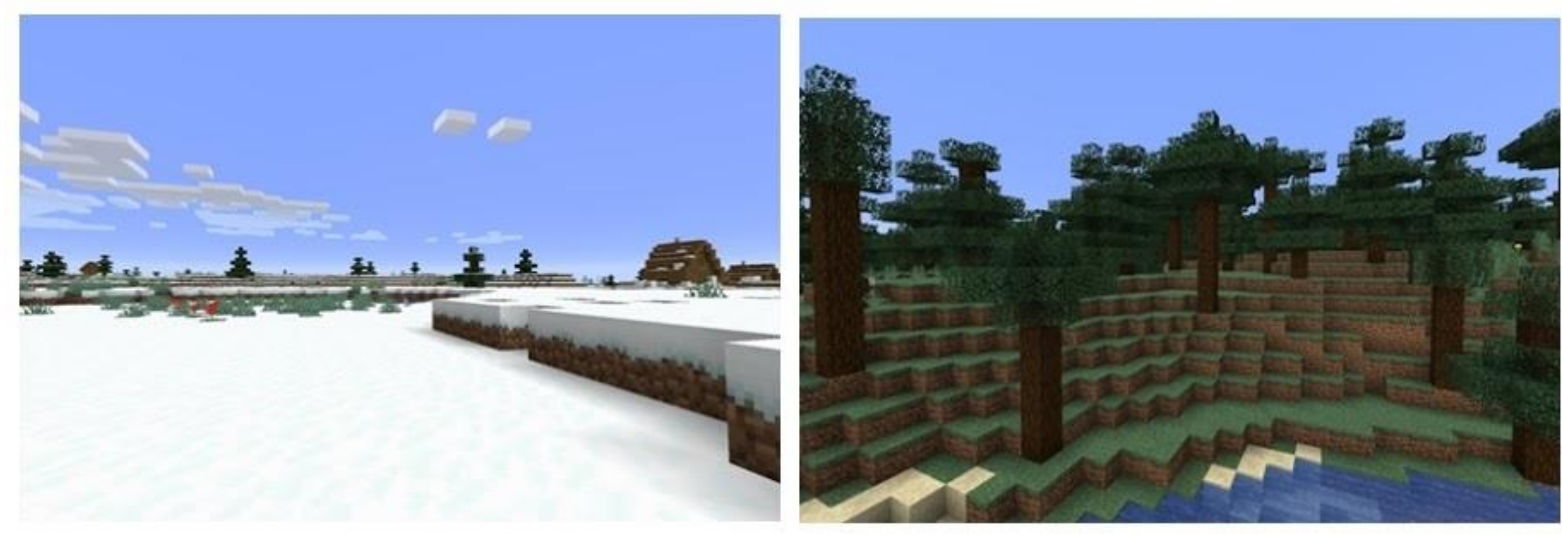

Fig. 5: Bioma de nieve "Tundra Nevada" (izquierda). Bioma frío "Taiga" (derecha) Fuente: Minecraft Gamepedia 

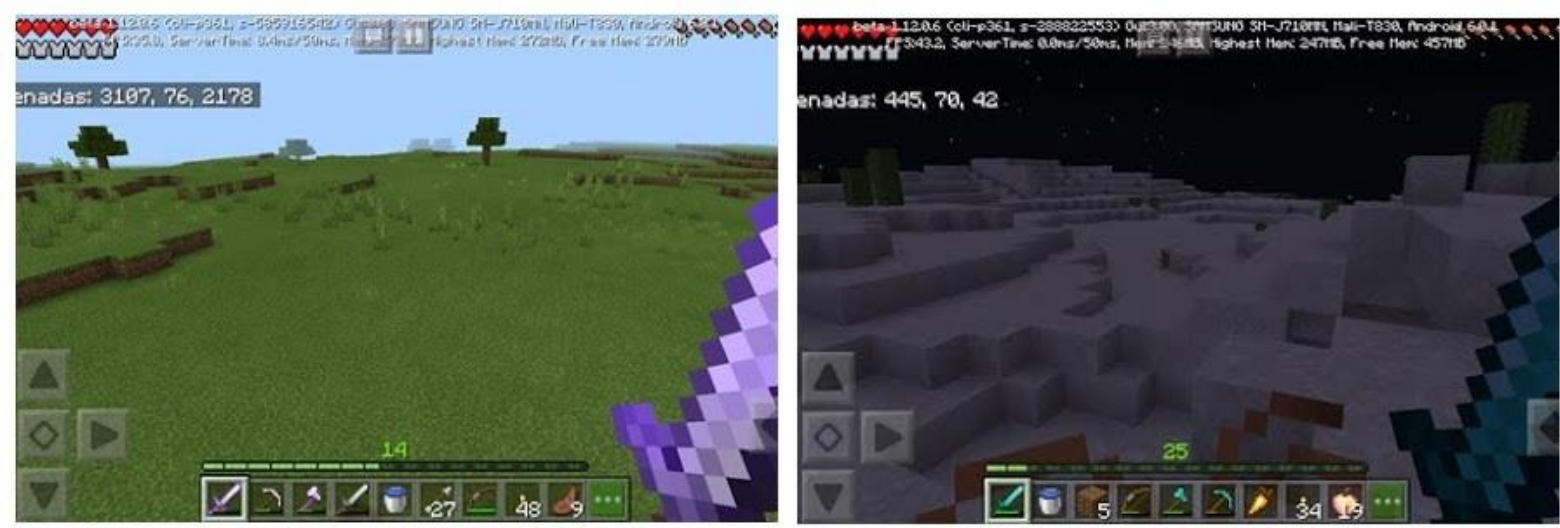

Fig. 6: Bioma medio "Llanura" (izquierda). Bioma seco "Desierto" (derecha)

Fuente: Captura de pantalla obtenida de Minecraft por los autores.

Con el aprendizaje de estos temas biogeográficos en el aula mediante el juego, se afianzan las habilidades y competencias que permiten describir y analizar las condiciones geográficas en relación con otros contenidos de disciplinas como la biología, ecología, geología, entre otros, para desarrollar un marco conceptual y metodológico que permita a los estudiantes desarrollar estudios integrales acerca de la distribución, en escala geográfica, de los organismos. Todo esto, como fundamento para formular y llevar a cabo estudios integrales como base para la planeación del manejo y conservación de la biodiversidad, así como para el aprovechamiento sustentable de los recursos (SEP, 2018). En general, fortalecer sus conocimientos sobre la distribución de los seres vivos, así como los procesos que la han originado y que la modifican, así como realizar el análisis de un Espacio Geográfico.

\section{Geomorfología}

\section{Procesos endógenos:}

Dentro del juego se encuentran bloques representantes de rocas, sedimentos, minerales y metales.

Los minerales que se encuentran son carbón, lapislázuli, diamante, esmeralda y cuarzo; "redstone" es un mineral ficticio. Los metales que se encuentran son oro y hierro (Fig. 7). Estos se encuentran en distintas profundidades (por ejemplo, los diamantes se encuentran debajo del nivel 11) y cantidades distintas haciendo que algunos sean más raros que otros (oro, diamante y esmeralda siendo los más raros). Por otra parte, en algunos biomas aumenta las posibilidades de encontrar ciertos minerales, por ejemplo, oro en los biomas de mesa o esmeralda en los biomas de montaña. La cantidad y diversidad de minerales que se pueden encontrar aumenta según su aproximación a la lava; si bien en la realidad existe una diferencia entre magma y lava, este elemento en el diseño del juego ayuda a los jugadores a entender la importancia de las cámaras magmáticas para la creación de minerales en la realidad.

Estos pueden ser utilizados para la fabricación de objetos, armas (espadas, ballestas, etc.), herramientas (hachas, picos, palas, etc.) y armaduras (cascos, petos, perneras y botas). Dependiendo del material utilizado es la duración del objeto, siendo el diamante el cual otorga una mayor duración y eficiencia funcionando como un ejemplo de la escala de dureza de los minerales de Mohs, en la cual el diamante se encuentra en el orden 10 convirtiéndolo en el mineral más duro. 
Los bloques de sedimentos que encontramos son arena, arcilla y grava, con estos el jugador puede crear arenisca, vidrio (arena), ladrillos (arcilla) y concreto (grava, arena y agua). Los bloques de rocas que se encuentran son arenisca, arenisca roja, piedra, granito, diorita, andesita. Estos bloques son más abundantes y son utilizados como material de construcción por el jugador. La obsidiana, una roca vítrea de color oscuro formada cuando lava se enfría rápidamente (Tarbuck y Lutgens 2005:118), en el juego se "crea" poniendo un bloque de agua sobre lava.

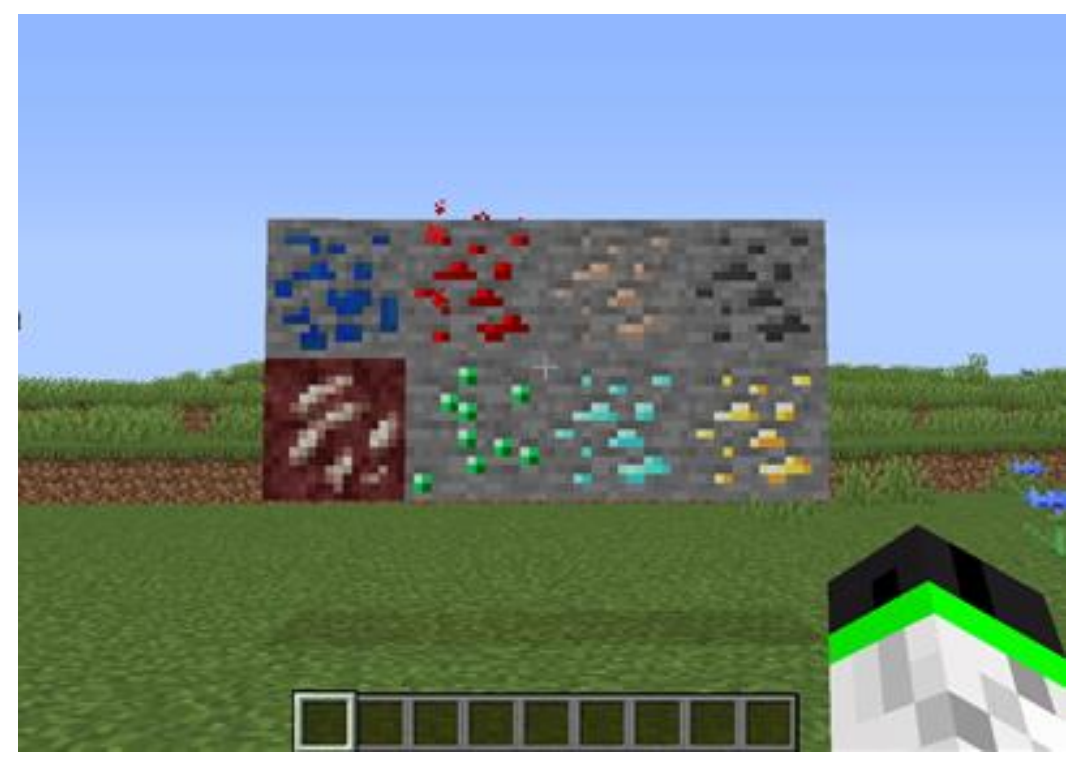

Fig. 7: Minerales y metales presentes en el juego.

Arriba (de izquierda a derecha): lapislázuli, redstone, hierro, carbón. Abajo (de izquierda a derecha): cuarzo, esmeralda, diamante, oro.

Fuente: Captura de pantalla obtenida de Minecraft por los autores.

Con respecto a los estratos, los cuales Tarbuck y Lutgens (2005:664) definen como "capas paralelas de rocas sedimentarias", pueden diferenciarse claramente en los biomas de mesa, donde cada estrato está conformado por bloques de terracota de distintos colores (Fig. 8). Esto ayuda a los estudiantes a entender conceptos como la depositación de sedimentos a través del tiempo geológico y la Ley de Superposición de Nicolaus Steno (Tarbuck y Lutgens 2005:257).



Fig. 8: Badland Erosionado dentro del bioma de mesa.

Fuente: Minecraft Gamepedia 


\section{Procesos exógenos:}

En el juego, la generación del terreno crea estructuras naturales que poseen similitudes a distintas geoformas como colinas, pendientes pronunciadas, mesetas y playas en los mundos generados. (Fig. 9) Su presencia es puramente estética, pero familiariza al jugador/estudiante con ellas, su forma y composición, por ejemplo, en la playa se puede observar una geoforma de acumulación, siendo la arena el sedimento acumulado.

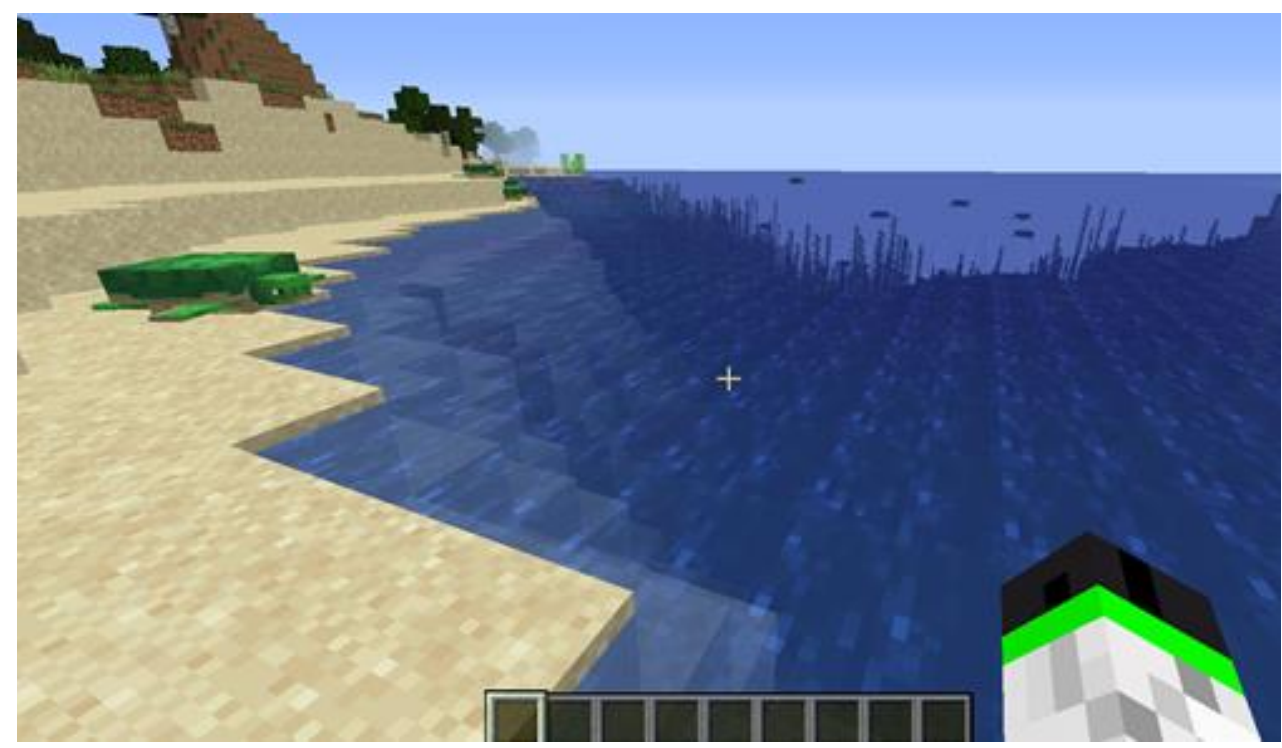

Fig. 9: Playa.

Fuente: Captura de pantalla obtenida de Minecraft por los autores.

Si bien, la Geomorfología no ha sido enseñada muy profundamente en el sistema educativo, es importante destacar que los conocimientos geomorfológicos y geológicos merecen un tratamiento más profundo, ejemplo de esto es la inclusión de asignaturas como Ciencias de la Tierra o Problemática Ambiental. Sus contenidos son relevantes bajo criterios que potencian la formación del estudiante, por sus cualidades y capacidad explicativa, no solo por estar organizado por leyes, teorías y principios, sino por los procedimientos que se utilizan para validar, generar o refutar ese cuerpo teórico y generar una utilidad futura, también por el tipo de formación que proporciona y poseer un interés social y económico, las cuestiones que aborda y las respuestas que ofrece. (Pedrinaci, 2014).

\section{Climatología}

En el juego, el tipo de clima depende del bioma; en el bioma del desierto nunca hay precipitaciones, en los biomas de nieve, precipita nieve y en los de pradera, bosque, océano, etc., llueve; sí llueve en un bioma de estos, al mismo tiempo estará nevando en los biomas de nieve, y el cielo estará oscuro en los desiertos (Fig. 10). Las variaciones en el tiempo atmosférico suelen ocurrir cada siete días dentro del juego y duran aproximadamente unos 15 minutos.

Los biomas tienen un valor de temperatura que determina si nieva, llueve o si está despejado. Los valores requeridos son menos de 0.15 para la nieve, 0.15 - 0.95 para la lluvia, o más de 1.0 para ninguno. Estos valores se pueden usar para determinar las alturas que genera la nieve en 
diferentes biomas porque la temperatura también disminuye según la altura, pero no cambia por debajo del nivel del mar.

Si bien el concepto de clima dentro del juego es extremadamente precario, le da al jugador/estudiante un entendimiento básico de cómo el clima varía en los distintos biomas según su temperatura.
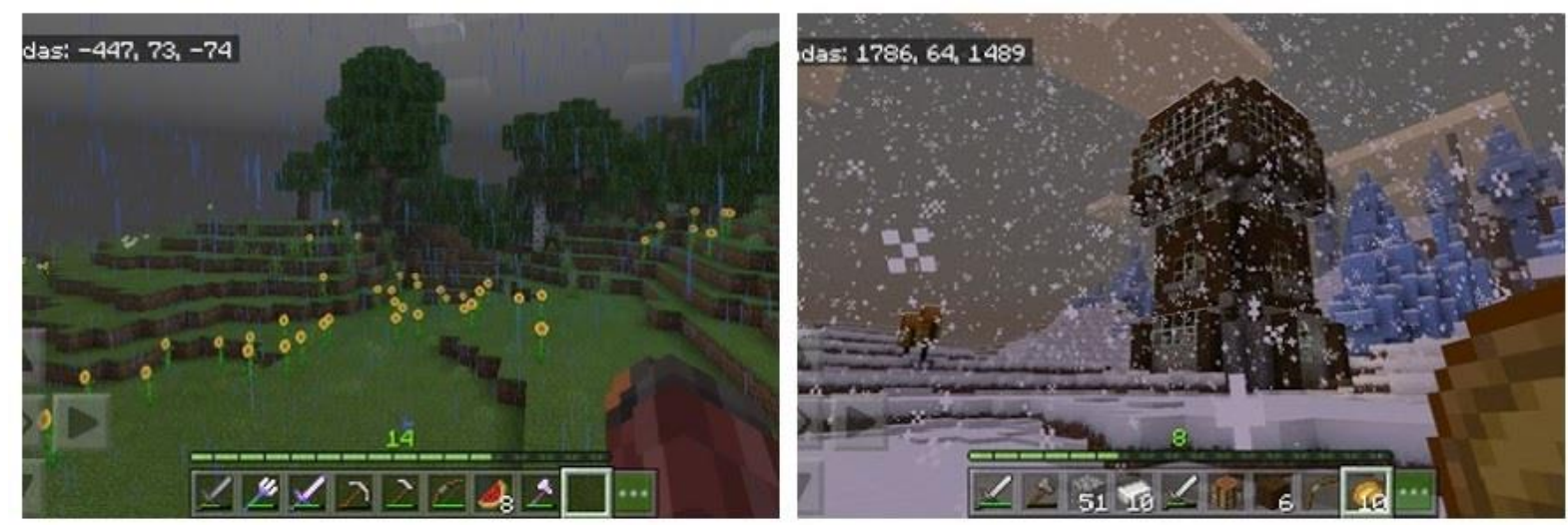

Fig. 10: Precipitaciones dentro del juego. (izquierda: lluvia / derecha: nieve)

Fuente: Captura de pantalla obtenida de Minecraft por los autores.

Según Martínez (2016), el estudio de la climatología constituye una tarea fundamental en la formación del alumnado en Educación. Primero, porque lo establecen los currículums vigentes, el tiempo atmosférico y el clima es un contenido a enseñar en todos los niveles educativos. Y segundo, debido a la enorme trascendencia social que tiene para gran parte de las actividades de la vida cotidiana. Estos temas están presentes en todos los medios de comunicación, es un tema recurrente en las conversaciones cotidianas, para planificar salidas etc., su conocimiento sigue siendo muy útil y necesario para la vida.

\section{Hidrografía}

En el juego, el océano es considerado como un bioma acuático, compuesto predominantemente de agua. Los océanos son los biomas de zonas más extensos, cubren entre un $25 \%$ y $33 \%$ de la superficie de un mundo al tener en cuenta todas sus variantes (opuesto a lo que se da en la realidad) y consiste en cuerpos de agua profundos con la superficie a una altitud de $Y=63$ por defecto, que se toma como el "nivel del mar" del mundo y el fondo del océano, se encuentra a una profundidad de aproximadamente $Y=45$. Estas altitudes fijas, especialmente el nivel del mar, ayuda al jugador a familiarizarse con el mismo fenómeno en la realidad.

El fondo marino es bastante montañoso (Fig. 11), con múltiples picos y valles, y está compuesto principalmente de grava, aunque se pueden generar algunos parches de arcilla, tierra y arena cerca de los picos. Los barrancos se pueden generar ocasionalmente en el fondo del océano, forman trincheras submarinas y se encuentran bloques de magma, creando columnas de burbujas de remolino que pueden arrastrar a un jugador hacia abajo; la forma alargada y presencia de magma puede tomarse como un ejemplo de rift continental que en la realidad aparece en áreas de bordes de placas divergentes. Algunos picos del fondo marino pueden ser lo suficientemente altos como para formar islas en la superficie del océano. Estas islas son típicamente pequeñas playas que rodean un parche de un bioma común, como bosques o llanuras. El fondo marino puede estar cubierto de algas marinas y corales. 


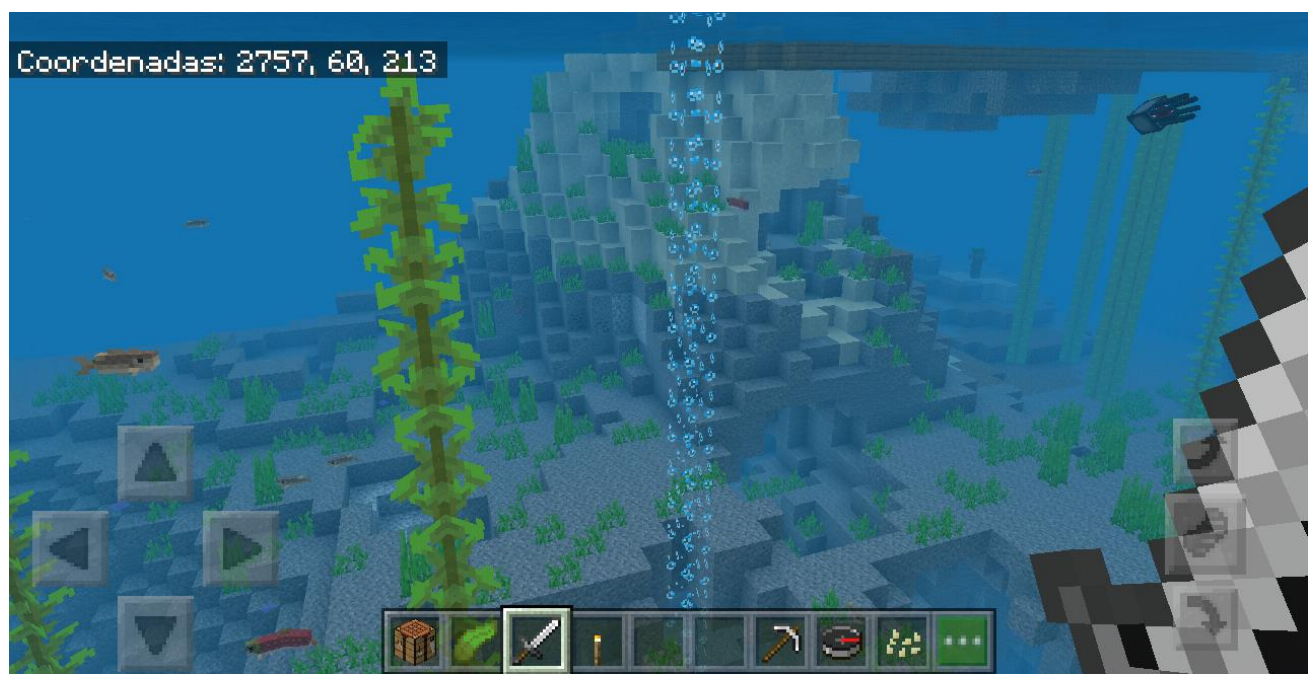

Fig. 11: Fondo marino.

Fuente: Captura de pantalla obtenida de Minecraft por los autores.

La variante Frozen Ocean (Océano Congelado) tiene agua púrpura oscura en la superficie. Al igual que el océano frío, tiene un fondo marino de grava, aunque la superficie del agua está mayormente congelada. Aquí no se encuentra vegetación marina en el fondo, dejándolo completamente estéril. Grandes icebergs hechos de bloques de nieve, hielo compacto y hielo azul se generan con frecuencia en la superficie. (Fig. 12)

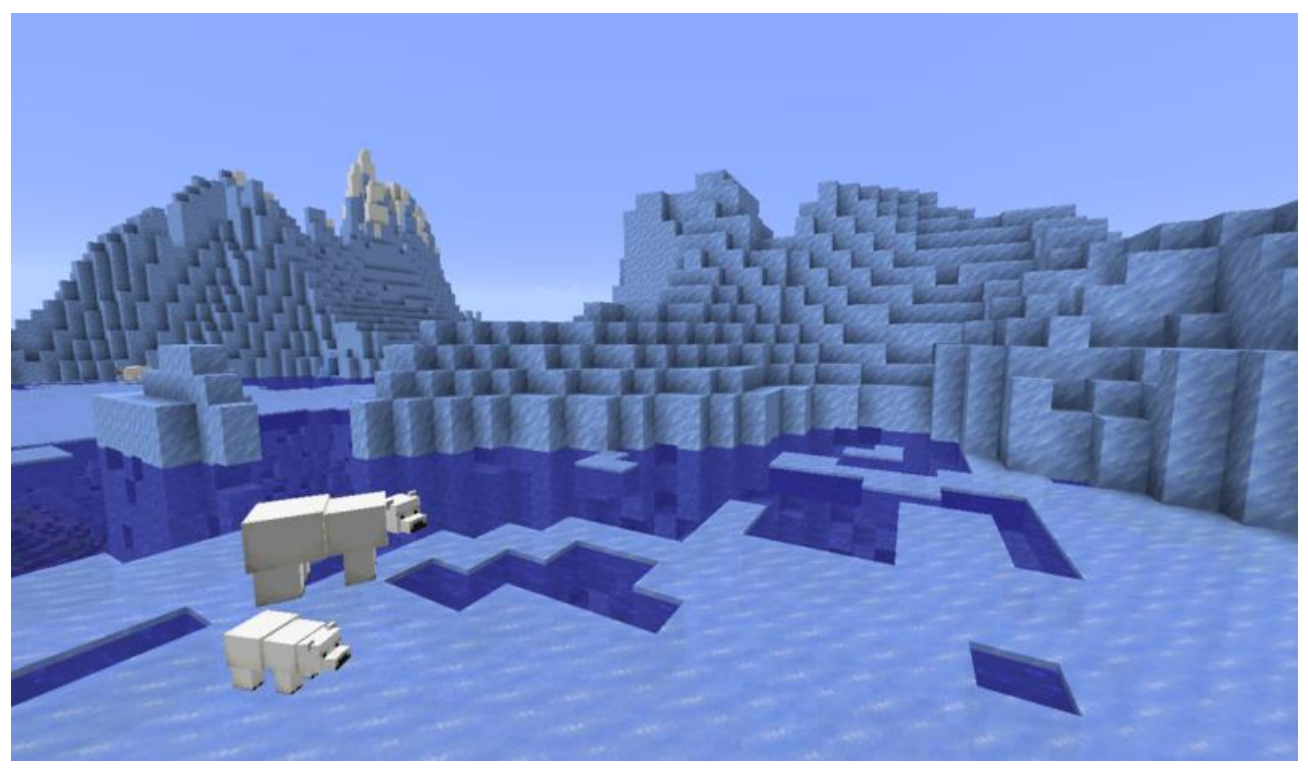

Fig. 12: Océano congelado.

Fuente: Minecraft Gamepedia

En el juego, los ríos son considerados como biomas delgados y largos que con frecuencia se generan en todo el mundo y generalmente conducen a los océanos (Figura 13), aunque ocasionalmente pueden formar círculos. Por lo general, sirven como una división entre dos biomas diferentes, pero también pueden dividir un solo bioma en dos. Están llenos de agua hasta el nivel del mar, aunque los ríos pueden secarse en ciertas áreas debido a una elevación más alta de lo habitual. Los cauces de los ríos consisten en tierra, arena, grava y arcilla que 
pueden ser tomados como ejemplos de los sedimentos que se depositan en las orillas y fondo de los ríos.

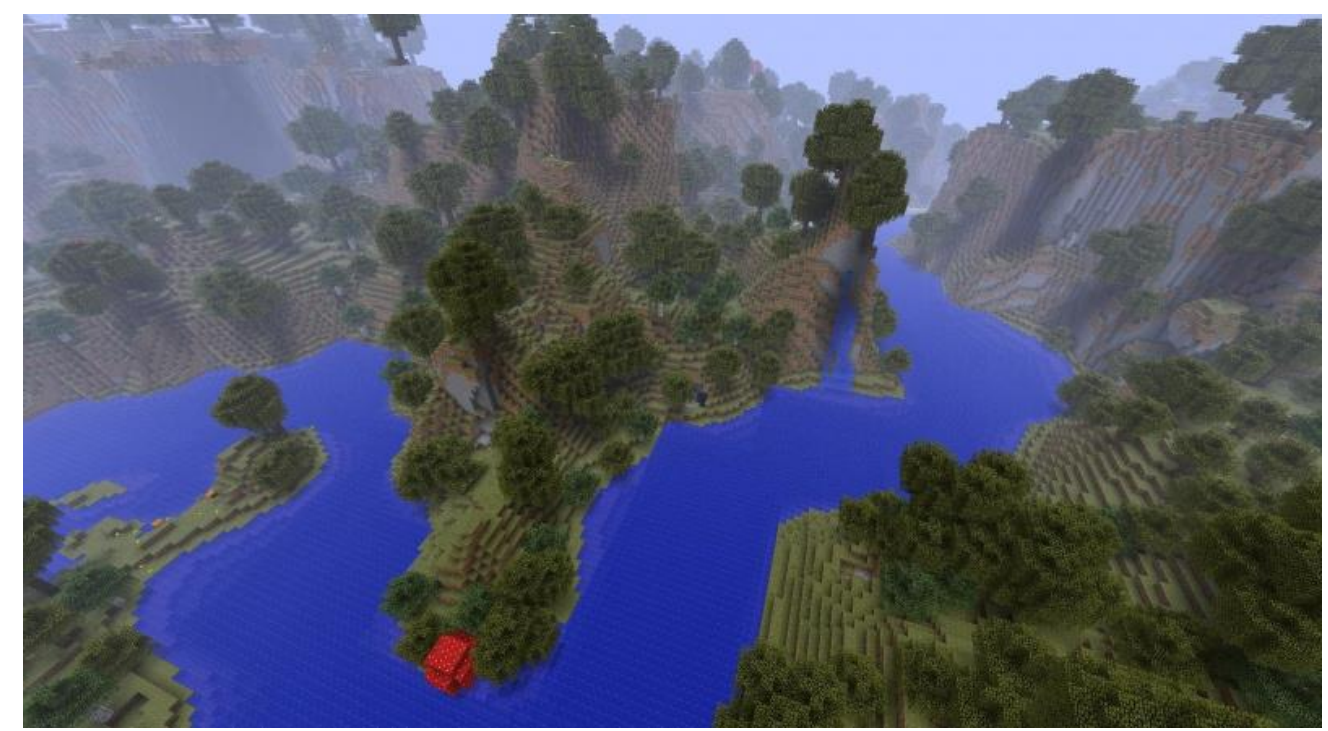

Fig. 13: Generación de un río en beta 1.8, una de las primeras imágenes publicadas por Notch. Fuente: Minecraft Gamepedia

Dado que el agua existe en la naturaleza en formas diversas y en muy diferentes lugares, su estudio es importante en relación con diversas disciplinas y ocupaciones, por ello es importante que los estudiantes posean una formación general que los capacite para observar y dar significado a los fenómenos hidrológicos, debido a que es una ciencia esencial para la planificación y diseño del desarrollo de los recursos hídricos. (UNESCO, 1975)

\section{Espacio Geográfico urbano y rural}

Por otra parte, en relación a la intervención del hombre y/o sociedad en la transformación de la naturaleza, se destaca la conformación de un Espacio Geográfico rural y un Espacio Geográfico urbano. En cuanto al estudio de estos Espacios Geográficos, la Geografía rural y la Geografía urbana se encargan de la descripción, análisis, interpretación, clasificación, entre otros, de los mismos. En el mundo originado en Minecraft es posible distinguir algunos de estos aspectos vinculados al campo y la ciudad.

\section{Geografía Rural}

En lo que respecta a la Geografía rural, se identificaron actividades relacionadas con la agricultura y la ganadería. Dentro de las aldeas, se pueden encontrar diferentes cultivos de: trigo, calabazas, papas, sandías, zanahorias, remolachas, caña de azúcar, cacao, bayas dulces y cactus. A su vez, el jugador puede generar sus propios cultivos en el lugar que desee, siempre y cuando se realice sobre tierra de cultivo, la cual se puede obtener utilizando una azada sobre un bloque de tierra. (Fig. 14)

Diferentes cultivos tienen distintos usos (por ejemplo, crear alimentos como pan para el consumo del jugador o tintes para teñir lana) y requisitos de espacio y cercanía a una fuente de agua, lo cual obliga al jugador ordenar el Espacio Geográfico. 




Figura 14: Cultivos de remolachas, trigo, calabazas y sandias.

Fuente: Captura de pantalla obtenida de Minecraft por los autores.

Por otro lado, se pueden llevar a cabo actividades ganaderas con animales cerdos, ovejas, vacas, burros, gallinas, caballos y llamas. Se aprovecha su carne, lana, cuero, huevos, plumas o leche (Fig. 15). Para la reproducción de los animales el jugador debe alimentarlos con cultivos específicos, por ejemplo, trigo para las ovejas, zanahorias para los cerdos o semillas para las gallinas.

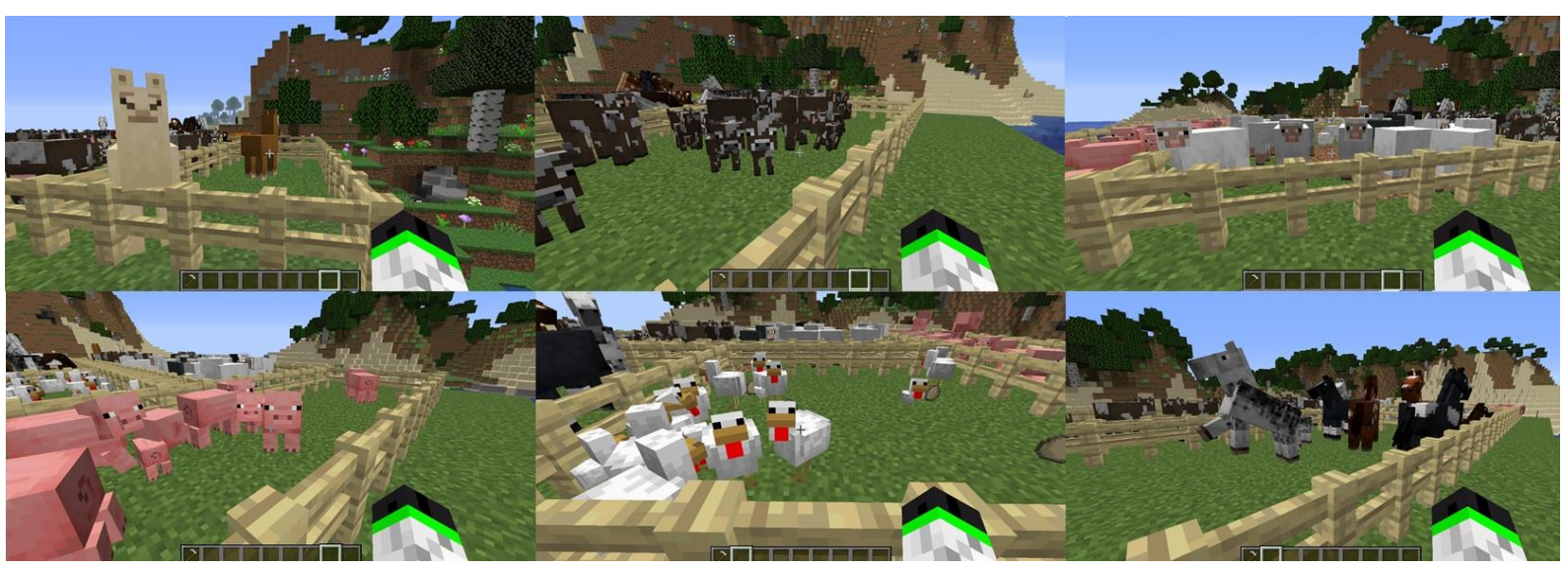

Fig. 15: Ganadería en Minecraft.

Fuente: Captura de pantalla obtenida de Minecraft por los autores.

Algunos animales deben de ser protegidos de depredadores, ya que su presencia suele atraerlos, como es el caso de las gallinas, que atraen a los zorros. Esto influye en las edificaciones que el jugador debe construir para proteger el ganado. Algunos animales generan un impacto en el espacio como, por ejemplo, las ovejas que comen hierba para que crezca su lana, una vez consumida la hierba deja un bloque de tierra sin cobertura vegetal; lo que le da al jugador/estudiante una noción del impacto que ciertas actividades económicas pueden tener en el Espacio Geográfico.

\section{Geografía Urbana}

Los elementos relacionados con la Geografía urbana son las aldeas (Fig. 16). Estas son generadas de manera natural en los biomas de llanuras, sabanas, taiga, tundra y desierto. El bioma en el centro de la aldea, determina el tipo de aldea y, por lo tanto, el estilo de todas las 
estructuras dentro de ella. Suelen encontrarse aldeanos, gatos, golems de hierro, quienes protegen la aldea y aldeanos. La función principal de las aldeas es la de proveer al jugador recursos e intercambios comerciales con los aldeanos.

El centro de la aldea está marcado con una estructura, ya sea natural (un árbol) o antrópica (un pozo de agua) en el cual se encuentra una campana. El centro también funciona como punto de encuentro, en el cual los aldeanos se reúnen una vez al día. En cercanías al centro de la aldea, también suele encontrarse un mercado cuya función es meramente decorativa y un edificio religioso (generalmente una iglesia). Esta característica hace que el centro de la aldea sea similar al concepto de "Centro Urbano" al ser el más animado y frecuentado (Grupo ADUAR 2000), se puede asumir que cumplen funciones administrativas, religiosas, políticas, culturales y comerciales.

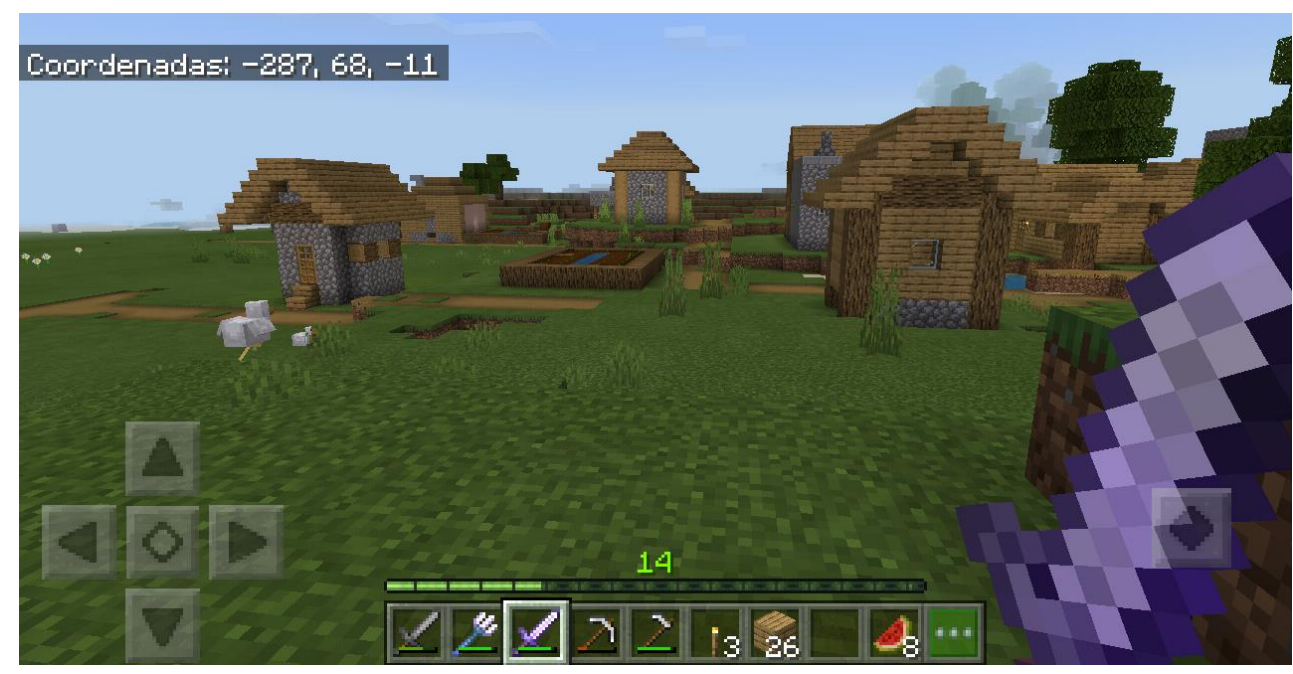

Fig. 16: Aldea.

Fuente: Captura de pantalla obtenida de Minecraft por los autores.

El número de edificios, de postes de lámparas y estructuras decorativas (fardos de heno, cultivos, etc.) es aleatorio y son ubicados en espacios donde no se pueden colocar otros edificios. No todos los edificios se pueden generar en una sola aldea, lo que produce que cada aldea sea única en la combinación de servicios que brinda al jugador.

El estilo de la arquitectura y los bloques que componen las estructuras de una aldea varía según su tipo (Fig. 17). Las aldeas generan caminos entre los edificios y se extienden fuera de ella, estos son utilizados por los aldeanos para trasladarse de su lugar de residencia (el punto donde se encuentra la cama que en la que duermen de noche), al centro de la aldea y su lugar de trabajo (determinado por la profesión del aldeano). 


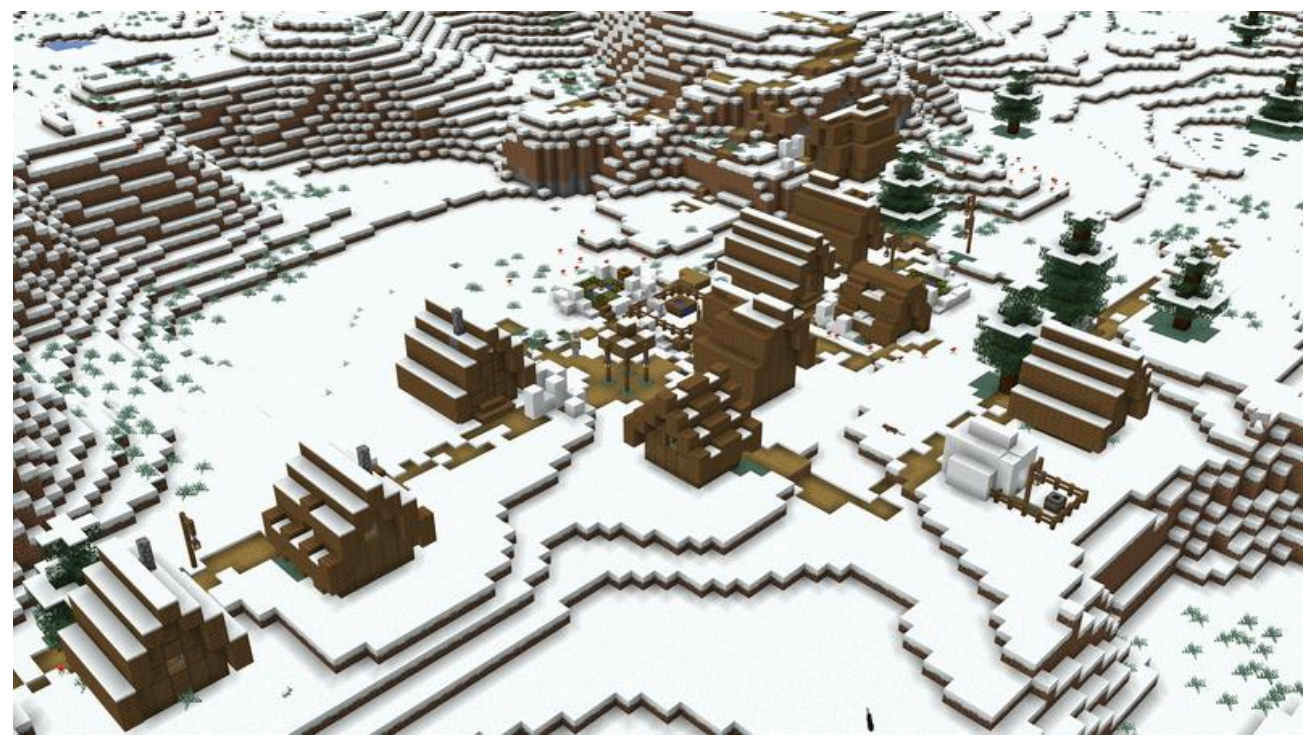

Fig. 17: Aldea generada en un bioma de tundra nevada.

Fuente: Minecraft Gamepedia

La enseñanza de la Geografía rural y de la urbana en la educación, requieren una actualización de los conocimientos, tanto conceptuales como procedimentales. Por ello, se considera que se pueden valorar los conocimientos que esta herramienta pedagógico-didáctica con sus características de aprendizaje game-based learning (GBL) pueda aportar sobre las prácticas docentes, promoviendo desde el proyecto procesos reflexivos para que se reconozca la necesidad de construir nuevos esquemas conceptuales y elaborar propuestas didácticas innovadoras para abordar los contenidos rurales y urbanos. (D’Angelo. 2011)

\section{Discusión}

De forma innata el videojuego Minecraft posee todas las características del Espacio Geográfico que puede abordarse de forma integral en relación a los aspectos físicos y naturales, como los humanos y sociales dentro de la Geografía, teniendo en cuenta las posibilidades de analizar las interrelaciones que se producen y enfatizando en una visión más integral y holística del espacio. El uso de un videojuego con las características mencionadas anteriormente, tiene un potencial relevante para la enseñanza de la Geografía, de una forma inusual e innovadora. Los distintos rasgos geográficos encontrados en el mismo siguen la lógica de la realidad, por lo cual funciona sin inconvenientes como una herramienta pedagógico-didáctica que aborda los elementos y las características del Espacio Geográfico, sus componentes naturales y sociales y, si lo requiere, puede ejecutarse en distintos niveles de enseñanza sin necesidad de realizar modificaciones externas a la estructura base del juego.

En virtud de la segmentación que puede producirse de los elementos y componentes del Espacio Geográfico en el juego, es importante, al momento de utilizarlo como una herramienta para el aprendizaje, que se pueda lograr una integración de estos elementos, concibiendo la lógica del Espacio Geográfico construido socialmente, en donde existen agentes que le otorgan dinámica y que son protagonistas de los espacios-escenarios que el videojuego nos propone. Por este motivo, será deber del docente guiar al alumno para que éste no vea los elementos geográficos de forma aislada, sino como un sistema de relaciones entre sí, con la sociedad incluida, enfatizando en una visión más integral del espacio y sus interrelaciones. 
Es relevante considerar el acercamiento de los estudiantes a la Geografía y sus campos y temáticas de estudio a partir del videojuego que utiliza un espacio virtual con características del Espacio Geográfico real. Este es un recurso didáctico innovador y se lo puede considerar una estrategia para despertar la atención en relación al aprendizaje de la ciencia geográfica.

\section{CONCLUSIONES}

El mundo generado de forma aleatoria por Minecraft posee todas las características del Espacio Geográfico. Se identifican elementos naturales y sociales que pueden abordarse desde la Geografía.

Por este motivo, Minecraft es una herramienta pedagógica y didáctica que puede ser utilizada para la enseñanza de la Geografía en distintos niveles. Se destaca su potencial para manifestar la motivación por el aprendizaje geográfico y lograr que surja una aceptación al lograr un cambio positivo del uso serio de videojuegos para los procesos de enseñanza-aprendizaje.

Se considera importante incluir la aplicación de videojuegos como recurso educativo en la enseñanza, ya que fortalece el proceso de aprendizaje en los estudiantes y contribuye a generar nuevas formas de educar.

Por otro lado, es necesario considerar romper con el estigma de pensar a los videojuegos como algo negativo para la enseñanza y demostrar el potencial educativo positivo de los juegos, que aportan a desarrollar y proporcionar al estudiante una forma de desenvolverse y experimentar de otro modo, al ser parte activa de su proceso de aprendizaje en lugar de ser solo un receptor pasivo.

\section{REFERENCIAS}

AMORÓS HERNÁNDEZ, A. (2016) “La representación cartográfica como recurso didáctico. Mapas y planas en educación primaria" Propuesta didáctica, Facultad de Educación. Universidad de Alicante.

BOSQUE MAUREL, J.; GARCÍA BALLESTEROS, A. (2003) "Miltos de Almeida Santos (1926-2001)”. Anales de Geografía de la Universidad Complutense. Pp. 9-19. Disponible en https://dialnet.unirioja.es/servlet/articulo?codigo=976054

D’ANGELO, M. L.; LOSSIO, O. (2011) "Innovar en la enseñanza de Geografía rural en la escuela secundaria: propuesta de desarrollo profesional docente." Revista Geográfica de América Central Número Especial EGAL, 2011- Costa Rica II Semestre 2011 pp. 112.

DOLLFUS, O. (1982) “El Espacio Geográfico”. Editorial Oikus Tau. Barcelona. España.

ENGELI, M. (2004) "Review of the book Rules of Play: Game Design Fundamentals". Leonardo 37. Disponible en: https://www.muse.jhu.edu/article/173410.

GAlleGO, F.; VILlAGRÁ, C.; SATORRE, R.; COMPAÑ, P.; MOLINA, RAFAEL y LLORENS, F. (2014) "Panorámica: serious games, gamification y mucho más". Universidad de Alicante. ReVisión vol. 7.

GARCÍA FERNÁNDEZ, F. (2005) "Videojuegos: un análisis desde el punto de vista educativo". Disponible en: https://www.academia.edu/6879703/Videojuegos_un_an\%C3\%A1lisis_desde_el_punt o_de_vista_educativo 
GÉRTRUDIX, M.; GÉRTRUDIX BARRIO, F. (2013) “Aprender jugando. Mundos inmersivos abiertos como espacios de aprendizaje de los y las jóvenes". Revista de estudios de Juventud. Vol. 101. págs 123-137.

GÓMEZ MENDOZA, J.; MUÑOZ GIMÉNEZ, J.; ORTEGA CANTERO N. (1982) “ $E l$ pensamiento geográfico" Editorial Alianza. Madrid. España.

GRUPO ADUAR (2000) "Diccionario de la Geografia urbana, urbanismo y ordenación del territorio” Editorial Ariel. Barcelona. España.

JOFRÉ, A. (1994) “Geografía Ambiental y Sociodemográfica. Editorial Universidad Abierta y a la Distancia Hernandarias". Buenos Aires. Argentina.

MARTINEZ MEDINA, R; LÓPEZ FERNÁNDEZ, J. A. (2016) "La enseñanza de la climatología en los manuales escolares de ciencias sociales en educación" en "La investigación e innovación en la enseñanza de la Geografia” Rafael Sebastiá Alcaraz, Emilia María Tonda Monllor (Eds.) editorial UNE

MCFARLANE, A.; PARROWHAWK, A.; HEALD, Y. (2002) "Report on the educational use of games".

MASTRANGELO, V. A., (2009) Análisis del concepto de recursos naturales en dos estudios de caso en Argentina. Revista Ambiente y Sociedade, Campinas v. XII, n 2 p. 341-355

OLIVIER, S. (1981) "Ecología y subdesarrollo en América Latina”. Siglo Veintiuno Eds. México D.F., México.

PEDRINACI, E. (2014) "La Geología en la Educación Secundaria: Situación Actual y Perspectivas" artículo IES de Gines (Sevilla) macla. $\mathrm{n}^{\circ}$ 14. junio’14 revista de la sociedad española de mineralogía.

PIERRE, G. (2007) "Diccionario Akal de Geografía" Editorial Akal. Madrid. España.

RESOLUCIÓN N²14/04 (2004) Consejo Federal de Cultura y Educación (CFCyE).

RODRÍGUEZ DE GONZÁLEZ, M; PARRA DE JURI, G.; CORAZZA, P. (2008) "Introducción a la Geografía". Material de cátedra. Universidad Nacional de Cuyo. Facultad de Filosofía y Letras. Departamento de Geografía.

SALEN, K.; ZIMMERMAN, E. (2004) "Rules of Play: Game Design Fundamentals" Cambridge, MA, USA. MIT Press.

SECRETARIA DE EDUCACIÓN PÚBLICA, (SEP) (2018) "Licenciatura en Enseñanza y Aprendizaje de la Biología en Educación Secundaria" Programa del curso BioGeografía. Ciudad de México.

SHAFFER, D.; HALVERSON, R.; SQUIRE, K.; GEE, J. (2005) "Video Games and the Future of Learning". Wisconsin Center for Education Research. Working Paper No. 2005-4.

TARBUCK, E. J.; LUTGENS, F. K. (2005) “CIENCIAS DE LA TIERRA: Una introducción a la Geología Física”. Pearson Educación S. A., Madrid, 2005

UNESCO (1975) "La enseñanza de la hidrología” contribuciones técnicas sobre la hidrología, contribución al Decenio Hidrológico Internacional. París.

VILÁ VALENTÍ, J. (1983) "Introducción al estudio teórico de la Geografía”. Editorial Ariel Geografía. Barcelona. España.

PERSSON, M. [@Notch] (2011, junio 2) “Dungeon Keeper is available at gog.com right now! It's one of the inspirations for Minecraft." [Tweet]. Twitter. Disponible en https://twitter.com/notch/status/76378826137018369. Consultado: 7/11/19

Referencia: Cuenta de Twitter Verificada de Notch. (Dungeon Keeper inspiración para Minecraft). 


\section{SITIOS WEB}

https://www.minecraft.net/es-es/

Referencia: Página oficial de Minecraft. Consultado el día 1/11/2019.

https://www.game-learn.com/la-teoria-del-game-based-learning/

Referencia: Página oficial de "Game Learn" Empresa de Game-based learning online, s/f. Consultado el día 7/11/2019.

https://go.inserver.es/blog/diferencia-entre-gamificacion-y-game-based-learning

Referencia: concepto Game based learning. Consultado el día 7/11/2019

https://www.minecraft-es.gamepedia.com

Referencia: Biomas de Minecraft, Edición Java. Consultado el día 8/11/2019

https://www.mojang.com/

Referencia: Página Oficial de Mojang. Consultada el día 8/10/2019

https://vidiq.com/es/blog/post/pewdiepie-youtube-minecraft/

Referencia: "PewDiePie se acerca a 100 millones de suscriptores en YouTube debido a Minecraft" artículo periodístico por Rob Wilson en la página vidIQv. Consultado el día $15 / 11 / 2019$

https://notch.tumblr.com/post/227922045/the-origins-of-minecraft

Referencia: Tumblr personal de Markus Persson, "The Word of Notch". Consultado el día $15 / 11 / 2019$

https://twitter.com/notch/status/76378826137018369

Referencia: Cuenta de Twitter Verificada de Notch. (Dungeon Keeper inspiración para Minecraft).

https://minecraft.gamepedia.com/

Referencia: Wiki de Minecraft. Consultado en múltiples ocasiones.

https://www.minecraft.net/es-es/about-earth/

Referencia: Página Oficial de Minecraft Earth. Consultado 21/11/2019

https://www.marca.com/esports/otros-juegos/2019/09/16/5d7f9bfb22601d1e658b457a.html

Referencia: Página Diario digital Marca eSport. Consultado 20/11/2019 